\title{
Simulink Block Diagram of Sixth-order Model for Power System Dynamic Study
}

\author{
Prechanon Kumkratug
}

\begin{abstract}
The order model of synchronous generator plays very important roles of determine the accuracy of power system dynamic study. This paper presents the simulation and analysis of the sixth order model of synchronous generator for power system dynamic study by using Simulink. The mathematical model of stream turbine governor and exciter are also considered in this paper. The presented method is tested on the single machine infinite bus system.
\end{abstract}

Index Terms - Power system, dynamic stability, MATLAB, Simulink.

\section{INTRODUCTION}

The dynamic behavior of power systems is important to both the system organizations, from an economic viewpoint, and reliability viewpoint. The power system dynamic study is one of the subject areas that has been increasing both in a graduate power engineering curricula and the power system industry. It is one of the subject areas that has been most affected by changing curricula patterns. It once formed the core of the power engineering syllabus. It is well known that the order model of the synchronous generator plays very important role to determine the accuracy of the simulation results [1].

There are two approaches of power system dynamic study. The first is referred to as the momentary mode. In this approach, all power system components including synchronous generator, exciter, and stream turbine are modeled in the detailed of three-phase sine functions. Most commercial software packages such as DigSilent, PSCAD, and EMTP are used this approach [2]-[3]. They are suitable for power engineering industry.

The second approach is called stability mode. In this approach, all power system components are model in the much simpler way by using one phase rms function [4]. This approach is very suitable for integrating in curricula. The numerical integration technique such as Euler's method is applied to visualize the dynamic behavior of the synchronous generator. Simulink is an interactive environment for modeling, analyzing, and simulating a wide variety of power system dynamic. It can be extended with bigger power system and the new components [5].

It is well known that the order model of the synchronous generator plays very important role to determine the accuracy of the simulation results. Reference [6], [7] used

Submitted on June 17, 2021.

Published on July 08, 2021.

Prechanon Kumkratug, Department of Electrical and Electronics

Engineering, Kasetsart University at Sriracha Campus, Chonburi,

Thailand.

(corresponding e-mail: prechanon@eng.src.ku.ac.th) the second-order model of synchronous generator Reference [8] used the third-order model. This paper will present Simulink block diagram of the sixth-order model of the synchronous generator. This paper has the following outline. Section II provides some a mathematical model of the synchronous generator, stream turbine governor, and exciter system. Section III presents the Simulink block diagram. In Section IV, the verification of the proposed control strategy and simulation method is tested on the sample system. Finally, conclusions are drawn in Section V.

\section{MATHEMATical Model}

\section{A. Synchronous Generator}

The second-order model of the synchronous generator is given by:

$\dot{\delta}_{i}=\Delta \omega_{i}$

$M_{i} \Delta \dot{\omega}_{i}=T_{m i}-T_{e i}-D_{i} \Delta \omega_{i}$

where

$\delta_{i}$ is the machine angle of the $i$-th machine

$\Delta \omega_{i}$ is the machine speed deviation of the $i$-th machine

$M_{i}$ is the moment of the inertia of the $i$-th machine

$D_{i}$ is the damping constant of the $i$-th machine

$T_{m i}, T_{e i}$ are the mechanical and electrical torque of the i-th machine.

The third-order model of the synchronous generator will include the $d$-axis voltage behind transient reactance of the $i$-th machine is written by:

$$
T_{q o i}^{\prime} \dot{E}_{d i}^{\prime}=-E_{d i}^{\prime}-\left(X_{q i}-X_{q i}^{\prime}\right) I_{q i}
$$

where

$E_{d i}^{\prime}$ is the $d$-axis voltage behind direct axis transient reactance ( $X_{d i}^{\prime}$ ) of the $i$-th machine;

$X_{q i}$ is the $q$-axis synchronous reactance of the $i$-th machine;

$I_{q i}$ is the $q$-axis terminal current of the $i$-th machine;

$T_{q o i}^{\prime}$ is the $q$-axis transient open circuit time constant of the $i$-th machine.

The fourth-order model of the synchronous generator will include the $q$-axis voltage behind transient reactance of the $i$-th machine is written by [9]:

$$
T_{d o i}^{\prime} \dot{E}_{q i}^{\prime}=E_{f d i}-E_{q i}^{\prime}-\left(X_{d i}-X_{d i}^{\prime}\right) I_{d i}
$$


where

$E_{q i}^{\prime}$ is the $q$-axis voltage behind direct axis transient reactance $\left(X_{q i}^{\prime}\right)$ of the $i$-th machine;

$X_{d i}$ is the $d$-axis synchronous reactance of the $i$-th machine;

$I_{d i}$ is the $d$-axis terminal current of the $i$-th machine;

$T_{d o i}^{\prime}$ is the $d$-axis transient open circuit time constant of the $i$-th machine.

The fifth-order model of the synchronous generator will include the $q$-axis voltage behind sub-transient reactance of the $i$-th machine is written by [10]:

$$
T_{q o i}^{\prime \prime} \dot{E}_{d i}^{\prime \prime}=E_{d i}^{\prime}-E_{d i}^{\prime \prime}+\left(X_{q i}^{\prime}-X_{q i}^{\prime \prime}\right) I_{q i}
$$

where

$E_{d i}^{\prime \prime}$ is the $d$-axis voltage behind direct axis sub-transient reactance $\left(X_{d i}^{\prime \prime}\right)$ of the $i$-th machine;

$T_{q o i}^{\prime \prime}$ is the $q$-axis sub-transient open circuit time constant of the $i$-th machine.

The sixth-order model of the synchronous generator will include the $q$-axis voltage behind sub-transient reactance of the $i$-th machine is written by

$$
T_{d o i}^{\prime \prime} \dot{E}_{q i}^{\prime \prime}=E_{q i}^{\prime}-E_{q i}^{\prime \prime}-\left(X_{d i}^{\prime}-X_{d i}^{\prime \prime}\right) I_{d i}
$$

where

$E_{q i}^{\prime \prime}$ is the $q$-axis voltage behind direct axis sub-transient reactance $\left(X_{q i}^{\prime \prime}\right)$ of the $i$-th machine;

$T_{d o i}^{\prime \prime}$ is the $d$-axis sub-transient open circuit time constant of the $i$-th machine.

\section{B. Stream Turbine}

The stream turbine consists of mechanical-hydraulic governors for stream turbines. It is not only designed mainly to maintain a constant speed by controlling the stream energy input to the turbines but also enhanced power system dynamic performances.

The nonlinear differential equations of the stream turbine are given by [9]:

$$
\begin{aligned}
& T_{S R} \dot{P}_{S}=-P_{S}+S R-\left(\Delta \omega / \omega_{b}\right) K_{G} \\
& T_{S M i} \dot{P}_{V}=-P_{V}+P_{S} \\
& T_{C H} \dot{P}_{H P}=-P_{H P}+P_{V} \\
& T_{C O} \dot{P}_{L P}=-P_{L P}+P_{I P} \\
& P_{m}=P_{H P} F_{H P}+P_{I P} F_{I P}+P_{L P} F_{L P}
\end{aligned}
$$

where

$P_{S}$ is the speed relay position;

$S_{R}$ is the signal reference;

$\omega_{b}$ is the speed base;

$K_{G}$ is the constant gain;
$T_{S R}$ is the time constant of the speed relay;

$T_{S M}$ is the time constant of the servo motor;

$P_{V}$ is the value position;

$P_{H P}$ is the mechanical power output of the high pressure turbine;

$P_{I P}$ is the mechanical power output of the medium pressure turbine;

$P_{L P}$ is the mechanical power output of the low pressure turbine;

$T_{C H}$ is the time constant of the stream chest;

$T_{R H i}$ is the time constant of the reheater;

$T_{C O}$ is the time constant of the crossover;

$F_{H P i}$ is the fraction power of the stream chest;

$F_{L P}$ is the fraction power of the reheater;

$F_{C O}$ is the fraction power of the crossover;

$P_{m}$ is the total machanical power.

\section{Exciter}

The exciter system is designed to maintain the synchronous generator voltage terminal and controls the reactive power flow.

The nonlinear differential equations of the exciter system are given by [11]:

$$
\begin{aligned}
& T_{R} \dot{V}_{O}=V_{t}-V_{O} \\
& T_{A} \dot{V}_{A}=K_{A}\left(V_{r e f}-V_{O}-V_{F}\right)-V_{A} \\
& T_{E} \dot{E}_{f d}=V_{A}-\left(K_{E}+S_{E}\right) E_{f d}
\end{aligned}
$$

$T_{F} \dot{V}_{F}=\frac{K_{F}}{T_{F}} E_{F}-V_{F}$

where

$V_{O}$ is the voltage sensor output;

$V_{t}$ is the terminal voltage;

$T_{R}$ is the voltage sensor time constant;

$V_{A}$ is the voltage regulator output;

$K_{A}$ is the voltage regulator gain;

$T_{A}$ is the voltage regulator time constant;

$V_{\text {ref }}$ is the voltage reference;

$V_{F}$ is the stabilizer voltage output;

$K_{E}$ is the exciter gain;

$T_{E}$ is the exciter time constant;

$S_{E}$ is the saturation function of the exciter.

\section{Simulink Block Diagram}

The differential equations of above equations can be written in the general form of state variables as

$$
\dot{x}_{n-1}=x_{n}
$$

$T_{n} \dot{x}_{n}=a_{1} x_{1}+a_{2} x_{2}+\ldots . a_{n} x_{n}+b_{1} u_{1}(t)+b_{2} u_{2}(t)+\ldots b_{j} u_{j}(t)$

where

$x$ is the variable;

$n$ is an $n$th order differential equation;

$T$ is the moment of inertia or time constant;

$a, b$ are the constant value; 
$u$ is the input.

The Simulink block diagram is dawn from the above state variables is shown in Fig. 1 and given by:

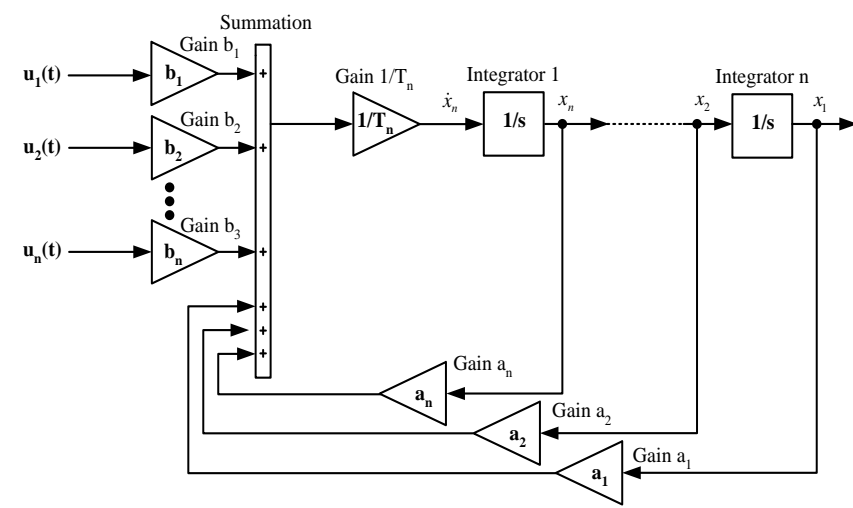

Fig. 1. Simulink block diagram representation for state equation of power system dynamic.

\section{Simulation Results}

Fig. 2 shows the single machine infinite bus system used to verify the proposed method. The following are the parameters in per unit on machine rating a 550 MVA, 20 $\mathrm{kV}, 60 \mathrm{~Hz}, 1800 \mathrm{RPM}$ turbine generator:

$$
\begin{aligned}
& H=3.7 \mathrm{MJ} / \mathrm{MVA}, X_{l}=0.15, X_{a d}=1.66, \\
& X_{d}=1.81, X_{q}=1.76, X_{d}^{\prime}=0.3002, X_{q}^{\prime}=0.5875, \\
& X_{d}^{\prime \prime}=0.23, X_{q}^{\prime \prime}=0.25, T_{d o}^{\prime}=8.2393, T_{q o}^{\prime}=1.195, \\
& T_{d o}^{\prime \prime}=0.0294, T_{q o}^{\prime \prime}=0.0586
\end{aligned}
$$

It is considered that a temporary three-phase fault occurs at bus 3 . The clearing fault time $\left(t_{c l}\right)$ used in this study is firstly $20 \mathrm{msec}$ and secondly $30 \mathrm{msec}$, respectively. Fig. 3 shows the swing curve of the system. It can be seen from the Fig. 3 and the (1)-(14) that the fault effect on the terminal voltage, terminal current, power flow, and synchronous generator speed thus results in dynamic response of the power system. The $t_{c l}$ is proportional to the magnitude of the swing curve. The magnitude of the swing curve of the $t_{c l}=$ $30 \mathrm{msec}$ is greater than that of $20 \mathrm{msec}$. However, the stream turbine consists of mechanical-hydraulic governors for stream turbines and the exciter system can maintain the system returning to the steady state almost at the same time. The setting time of both $t_{c l}=20 \mathrm{msec}$ and $t_{c l}=30 \mathrm{msec}$ is around $20 \mathrm{msec}$. It can be mentioned here that governors and exciter system can improve the dynamic behaviors of power system.

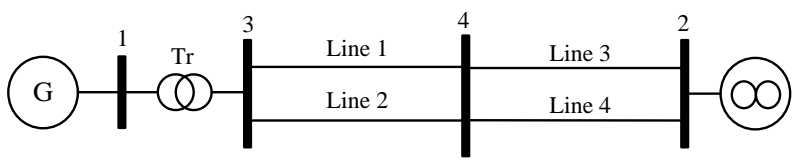

Fig. 2. Single machine infinite bus system.

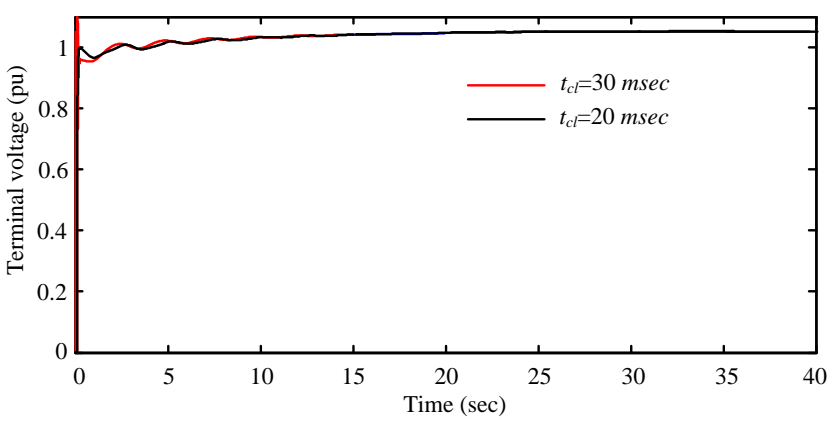

(a)

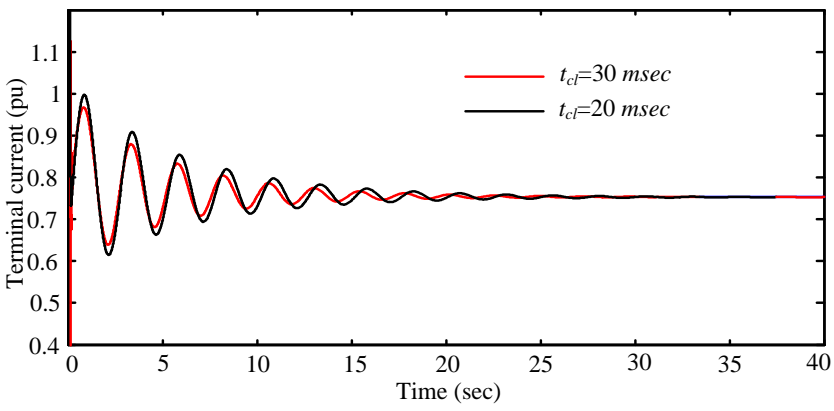

(b)

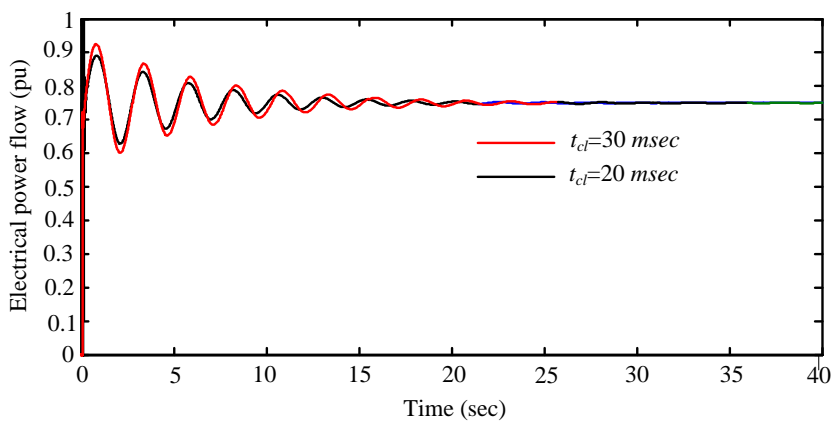

(c)

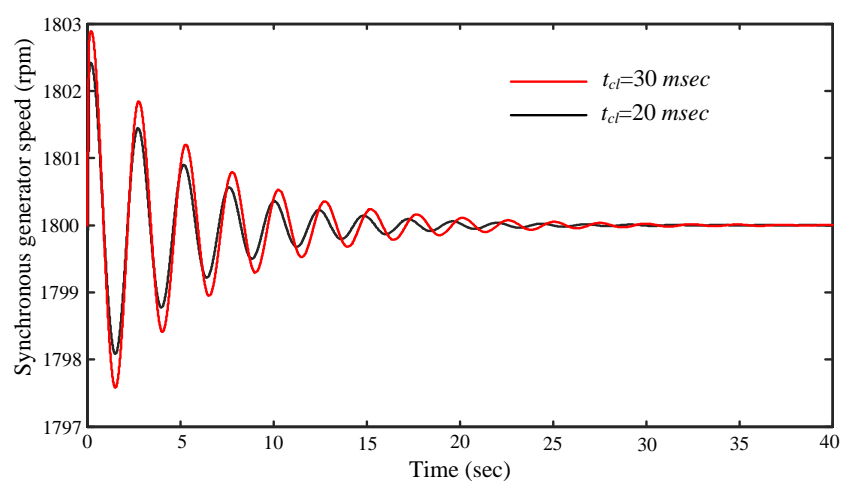

(d)

Fig. 3. The system with MTDC for the third case: (a) terminal voltage (b) terminal current (c) electrical power flow (d) synchronous generator speed.

\section{CONCLUSION}

This paper presented the method of analysis the sixthorder model of synchronous generator through Simulink. The presented method is based on the stability mode. Thus, the simulation time is much faster than the stability mode. In addition, it is also flexible for implement in the Simulink for power system dynamic study. It is very suitable for integrating in the classroom of graduate power engineering curricula. The dynamic behavior of the steam turbine and 
exciter system are also considered in this paper. The presented method was successfully tested on the sample system. It provided the perfect agreement.

\section{REFERENCES}

[1] P. Kundur, Power system stability and control, New York: McGrawHill, 1994, pp. 45-136.

[2] B. Hartmann and Sz. Lipták, "Development of steady state and dynamic energy storage models for DIgSILENT power factory," presented in IEEE Eindhoven Power Tech, Eindhoven, Netherlands, 2015.

[3] Y. Chen, M. Podlaski, J. Schmall, S. H. Haung, and M. Khan, "ERCOT PSCAD model review platform development and performance Comparison with PSS/e model," presented at the IEEE Power \& Energy Society General Meeting, Montreal, Canada, August 2-6, 2020.

[4] D. Povh, "Application of FACTS systems," presented in EPSOM, Zurich, Switzerland, 1998.

[5] Mathworks, Simulink

manual, https://www.mathworks.com/help/simulink/.

[6] A. Athay, R. Podmore, and S. Virmani, "A practical method for the direct analysis of transient stability," IEEE Trans. Power Syst., vol. PAS-98, no. 2, pp. 573-584, Mar-Apr. 1979.

[7] V. Azbe, U. Gabrijel, D. Povh, and R. Mihalic, "The energy function of a general multimachine system with a unified power flow controller," IEEE Trans. Power Syst., vol. 20, pp. 1478-1485, Aug. 2005.

[8] Z. Li, Y. Yang, and X. Baa, "Simulation and analysis of the thirdorder model of synchronous generator based on MFC," presented at International Conference on Mechatronics and Automation, Changchun, China, August 9-12, 2009.

[9] P. W. Sauer and M. A. Pai, Power system dynamics and stability, New Jersey: Prentice Hall, 2013, pp. 77-87.

[10] J. Machowski, J. W. Bialek, and J. R. Bumby, Power system dynamics stability and control, February 2020888 Pages.

[11] P. M. Anderson and A. A. Fouad, Power system control and stability, Iowa: The Iowa State University Press, 1977, pp. 83-148.

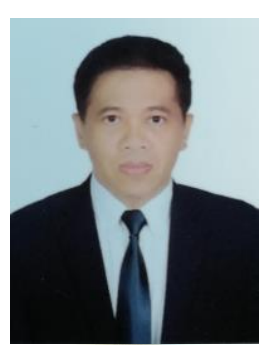

Prechanon Kumkratug received his B.E., M.E., and D.E. degrees from King Mongkut's Institute of Technology Ladkrabang, in 1996, Asian Institute of Technology, in 1999, and Kasetsart University at Bang Khean Campus, in 2008 respectively. His employment experience included the Advanced Info Services plc, Mahanakorn University, King Monkut's Institute of Technology Thonburi, and Eastern Asian University. $\mathrm{He}$ is currently employed as an Associate Professor at the Department of Electrical and Electronics Engineering, Kasetsart University, Sri Racha Campus. 